\title{
ESSE CINEMA COM CHEIRO: FILME E POESIA NOS MODERNISMOS PORTUGUÊS E BRASILEIRO
}

Joana Matos Frias

((Universidade do Porto)

\section{RESUMO}

Breve reflexão acerca das correlações entre cinema e poesia nas primeiras décadas do século XX em Portugal e no Brasil, com especial ênfase nos modos de recepção por parte dos escritores da época da nova manifestação artística e das suas expressões autorais menos previsíveis e mais singulares.

PALAVRAS-CHAVE: Cinema; poesia; modernismo; Limite; Douro, Faina Fluvial; Mário Peixoto; Manoel de Oliveira

Culpa sua ter exgottado litteratura viagens esse cinema com cheiro que é Pathé-Baby.

Oswald de Andrade, "Carta-oceano”(ouverture de Pathé-Baby, de Alcântara Machado) Dezembro de 1925

Em 1896, malgrado as dificuldades oferecidas pelos problemas eléctricos na cidade, o Rio de Janeiro assistia, à semelhança do que se observava numa série de outros países incluindo Portugal, à sua primeira exibição de cinema na Rua do Ouvidor; e também no Brasil se procederia a uma reprodução em contexto local de uma das conhecidas películas de estreia dos irmãos Lumière, com a Chegada do Trem a Petrópolis, de Vittorio di Maio, produzida e exibida no Cassino Fluminense em 1897, na que foi uma de muitas produções nacionais dos anos de estreia da nova arte, a que se sucederiam filmes como a película de Francisco Marzullo, Os Estranguladores, de 1906, com segunda versão em 1908 por Antonio Leal, ou o então célebre 
O Crime da Mala, também de 1908 (cf. Viany, 1959; Gonzaga, 1956 e 1958; Capellaro e Ferreira, 1996). Contudo, e tal como em Portugal, o que se fez em matéria de cinema entre 1896 e 1912 não foi muito além do que já havia sido cumprido por Affonso Segretto nos anos inaugurais da cinematografia brasileira, ${ }^{1}$ tendo-se verificado um conjunto significativo de alterações já na segunda metade da segunda década do século, bem flagrantes no nascimento de revistas da especialidade, desde a Cinearte, que, nos decénios seguintes, seria responsável pela proliferação de publicações periódicas similares e cada vez mais elaboradas, cujos produtos mais depurados viriam a lume já entre as décadas de 20 e 30, com destaque muito especial para o caso de $O$ Fan, órgão oficial do conhecido Chaplin-Club. ${ }^{2}$

Porém, o que talvez seja mais digno de nota neste contexto e neste período seja o facto de, no ano de 1931, tanto o cinema português como o brasileiro terem experienciado as primeiras manifestações verdadeiramente artísticas da nova arte: trata-se na verdade de uma espécie de annus mirabilis da cinematografia dos dois países, graças à estreia, em Portugal, de Manoel de Oliveira com a curta-metragem documental Douro, Faina Fluvial (cujo correspondente brasileiro poderia ser a película São Paulo, Sinfonia da Metrópole, de 1929) e, no Brasil, de Mário Peixoto com a longa-metragem ficcional Limite (a que se seguiria de imediato o também decisivo Ganga Bruta de Humberto Mauro, o preferido de Glauber Rocha), cuja fotografia ficara a cargo de Edgar Brasil, e que reunia na banda sonora musical peças de Erik Satie, Debussy, Ravel, Stravinsky e Prokofiev, entre outros. A História encarregar-se-ia de diferenciar radicalmente a obra dos dois realizadores (desaparecido em 2015, com 106 anos, Oliveira continuava a realizar filmes, contando com mais de 4 dezenas de títulos na sua filmografia, ao passo que Mário Peixoto deixou Limite como único exemplo acabado do seu talento e do seu génio, dado que Maré Baixa e Três contra o Mundo não seriam ultimados), mas o papel determinante que as obras de estreia de cada um desempenharam no pensamento estético da época pode e deve ser equacionado em conjunto, pois marca o momento em que, de uma forma consciente e aprofundada, os intelectuais de então se viram obrigados a assumir o carácter estético do cinema a partir do reconhecimento de que a nova arte podia produzir obras não narrativas, não resultantes da mera adaptação mecânica de enredos providenciados por romances conhecidos da História da Literatura, como acontecera em ambos os países nas primeiras décadas do século e sobretudo a partir de 1915, com especial destaque para as adaptações de obras 
de Camilo Castelo Branco e de José de Alencar respectivamente. Atentemos rapidamente nos termos utilizados por alguns desses pensadores ao procurarem apreender a singularidade excepcional das duas películas.

Logo em 1931, seria José Régio a perceber com uma agudeza que a distância histórica viria consolidar o papel excepcional que Manoel de Oliveira acabaria por desempenhar no panorama do cinema português, e que viria a contemplar, como ésabido, algumas das obras do próprio escritor (os filmes Benilde ou a Virgem Mãe, Mon Cas e O Quinto Império, e o documentário As Pinturas do Meu Irmão Julio). Poucos meses antes de conhecer pessoalmente o realizador pela mão de Casais Monteiro, Régio apregoava com entusiasmo que o filme de Oliveira era "uma poderosa visão de poeta", para concluir:

E todo o filme respira uma poesia que se não dirige a qualquer nosso banal pendor sentimentalista, - mas ao que de mais íntimo há na nossa humanidade e no nosso senso estético. (Régio, 1931,p. 15)

Três anos mais tarde, a propósito da estreia da versão sonora do filme, Régio acrescentaria que se tratava do "nosso melhor filme", retomando os termos com que o descrevera no texto precedente: "Manuel [sic] de Oliveira é artista e poeta, no alto sentido em que, afinal, estas duas palavras são sinónimas" (Régio, 1934). Ainda em 34, Régio valorizará no filme de Manoel de Oliveira "a moderna poesia do ferro e do aço", evidenciando assim que a sua perspectiva articulada das artes só era concebível com o epicentro localizável na Poesia, o que viria a estar subjacente ao testemunho epigramático de António Lopes Ribeiro de que "o cinema era para Régio poesia visível" (Ribeiro, 1970, p. 100). De facto, depois de ter postulado, no texto sobre Buster Keaton publicado no $\mathrm{n}^{\circ} 4$ da presença, que "novos contos fantásticos se contam hoje a toda a espécie de crianças", e que "estes são contados aos olhos", Régio dirá que "Charlot ultrapassa o cómico por ser um grande poeta", qualificando Chaplin, uns meses depois, no próprio "Literatura livresca e literatura viva", como "mestre de todos os poetas modernos". De forma ainda mais desconcertante, mas numa reflexão deixada em suspenso, em 1929 remata o ensaio sobre a poesia de Mário Saa, advertindo: "eu poderia agora, a propósito dos seus meios de expressão, falar em Chaplin e Keaton. Para quê? A indicação (é claro que insuficiente) aí fica" (Régio, 1929, p. 3).

É sabido que a história das três exibições de Limite por altura da sua produção em muito pouco se distingue da história da estreia do primeiro filme de Manoel de Oliveira, pois também Limite não se adequava ao gosto do 
público habituado às películas narrativas de inspiração hollywoodesca que já então dominavam a indústria cinematográfica de uma grande parte dos países ocidentais. ${ }^{3}$ Mas o caso de Limite parece ser ainda mais grave do que o de Douro, Faina Fluvial, pois até alguns espíritos muito antenados da época, como o eclético e cinéfilo Murilo Mendes que o qualificou de "canto do desânimo", ${ }_{4}^{4}$ tiveram grande dificuldade em apreciar a inovação estética que o filme de Peixoto necessariamente trazia ao panorama nacional (sem esquecer que, apesar de Alberto Cavalcanti ter já realizado um filme como Rien que les Heures, a sua circulação se restringira ao contexto europeu em que o realizador se encontrava na época). Destaquemos a este propósito, na senda da pesquisa levada a cabo por Filippi Fernandes, as palavras proferidas por José Lins do Rego alguns anos mais tarde:

Não cheguei a ver o tal Limite, mas pelas informações vim a ter certeza de que se trata de uma experiência de cinema literário, coisa que não me julgo capaz de criticar ou mesmo de assistir. Um rapaz de talento para a poesia resolveu realizar um poema de fotografias, de jogo de formas, e dizem que conseguiria juntar pedaços de celulóide, dando um conjunto de arte. Tudo isto é muito bonito, mas não é cinema, propriamente dito. É coisa para requintados, para as chamadas elites eleitas para o refinado gozo da arte pura. Quando me refiro a cinema eu imagino logo uma boa história, tratada por bons artistas, coisa que me faça emoção, que me ajude a viver, que me tome o tempo sem me meter em complicações teóricas sobre ângulos, luz, sombra, o diabo, enfim. Refiro-me ao cinema feito para o povo, como divertimento. E é tudo quanto eu quero para mim e que desejo para os outros. O mais é pacholice de literatos cacetes, quando não é doença inconfessável.

(O Globo, 4 de Maio de 1944; sublinhados meus)

Lins do Rego e Murilo Mendes não constituem, naturalmente, exemplos representativos da reacção que o filme de Peixoto provocou numa boa parte dos intelectuais dos anos 30, com destaque para o Octavio de Faria do famoso Chaplin-Club e, muito especialmente, para Vinicius de Moraes, que faria questão de exibir o filme a Orson Welles uns anos mais tarde, tendo mesmo declarado, numa síntese muito expressiva: "O Chaplin Club, de Otávio de Faria, Plínio Süssekind, Almir Castro e outros, [...] foi, com o filme Limite, de Mário Peixoto, a única coisa séria que tivemos em matéria de cinema no Brasil" (Moraes, 1941). ${ }^{5}$ Mas o que realmente importa na apreciação de Lins do Rego que transcrevi é constatarmos que, independentemente do 
juízo de gosto subjacente às palavras de Régio, no caso de Oliveira, e de Lins do Rego, no caso de Peixoto, ambos lançam mão de lexemas como "poesia", "poema" e "poeta"para tentarem diferenciar as duas películas das suas congéneres de expressão narrativa. ${ }^{6}$ Quer dizer que, ao contrariarem o princípio da "boa história" que Lins do Rego saudosamente evoca, quer Douro, Faina Fluvial quer Limite passam a integrar um género cinematográfico distinto que, à falta de melhor qualificação, deve ser identificado como poético (cf. Walls-Romana 2013). ${ }^{7} \mathrm{E}$ das apreciações de uns e de outros podemos então identificar quais os traços específicos deste género: trata-se de uma expressão artística visando aarte pela arte e respeitando o princípio kantiano da finalidade sem fim, rumo à concretização do que, à semelhança da poesia pura, poderia ser um eventual cinema puro - Vinicius conta, a propósito de Limite: "Carpeaux soprou-me ao ouvido: 'Mas é poesia pura..."” (Moraes, 1994, p. $60)^{8}$--, mediante a criação de um objecto artístico inteiramente assente na correlação estética entre as imagens, por meio da montagem que impõe o ritmo e que se estrutura com base no exercício esteticamente intencional do corte: "é por esta razão que a montagem pode [...] produzir poesia", há-de concluir Béla Balázs, que não deixa de mencionar "that lyrical film-poetry which is yet to be born" (1952,pp. 119 e 165). ${ }^{9}$ No caso de Oliveira como no de Peixoto, tal especificidade derivava, em termos de tradição e talento individual, de um intencional afastamento do cinema hollywoodesco da época, e de uma relação estética e estrutural muito consistente com a cinematografia russa de Vertov e de Eisenstein, bem como com a cinematografia germânica mais ou menos expressionista, muito em particular a de Murnau e a de Dreyer, e, sobretudo no caso de Peixoto, com o cinema impressionista francês ${ }^{10}$ do início dos anos 20, conforme notou de imediato o avisado Octavio de Faria:

Sua história é "de qualquer parte" como a de Aurora. Sua técnica é a mais moderna, internacional: sem letreiros (um ou dois, usados para evitar alongamentos), segundo a técnica de cenário dos alemães, máquina movendo-se como nos filmes americanos ou alemães, filme ritmado obedecendo a um montage entre o russo e o alemão, artistas sem maquilage, como em $A$ paixão de Joana d'Arc de Dreyer, como em Finis terrae de Epstein, como nos filmes russos.

[...] Limite não visa, em princípio, estudar costumes locais ou focalizar caracteres nacionais. Se o faz aqui e ali, é acidentalmente. Na verdade Limite interessa muito mais como filme em geral do que como filme nacional. E mais ainda como obra de CINEMA PURO do que como narração de 'casos' ou exploração de uma situação. 
[...] é um filme de imagens, sem preocupações sociais. Não expõe, não ataca, não defende, não analisa. Mostra apenas, relaciona coisas entre si no plano estético, sintetiza emoções.

O que talvez explique também que, quando em 1941 Vinicius de Moraes dá início à sua produção crítica em torno do cinema, com o ensaio "Credo e alarme" (por certo assumidamente apresentando bastantes ressonâncias do conhecido manifesto de Octavio de Faria, "Eu creio na imagem...", publicado no ${ }^{\circ} 6$ de $O$ Fan, emSetembro de $1929^{11}$ ), a sua escrita esteja já eivada desta metalinguagem, como se pode verificar logo nas primeiras linhas do texto:

Creio no Cinema, arte muda, filha da Imagem, elemento original de poesia e plástica infinitas, célula simples de duração efêmera e livremente multiplicável. Creio no Cinema, meio de expressão total em seu poder transmissor e sua capacidade de emoção, possuidor de uma forma própria que lhe é imanente e que, contendo todas as outras, nada lhes deve. Creio no Cinema puro, branco e preto, linguagem universal de alto valor sugestivo, rico na liberalidade e poder de evocação.

\section{$[\ldots]$}

ainda me resta uma esperança cega de vê-lo volver à origem, à Imagem em simples continuidade, ao jogo pródigo de sombras e claridades, ao ritmo interior, à Poesia que o fecunda, à Música que o envolve, à Pintura que o delimita, à Arquitetura que o constrói, à Palavra que o comenta, e que milagrosamente se ausentam para deixar vivo o que de exato se chama Cinema. (Moraes, 1994, p. 15)

E, depois de mostrar Limite a Orson Welles, Vinicius sintetizará, precisamente na mesma atmosfera lexical:

Limite é um anfiguri que toca os limites da intuição perfeita. Há constantemente a incursão do cinema na sucessão. O ritmo ora é largo, em grandes planejamentos, ora vertiginoso, sem a menor dispersão, com um mínimo de veículo na imagem. A imagem é a grande força presente, em ritmo interior e de sucessão, criando problemas permanentes na imaginação do espectador. Nunca se viu um filme tão carregado (e eu emprego o termo como ele é usado em eletricidade) de meaning, de expressão, de coisas para dizer, sem dizer nada, sem chegar nunca a revelar, deixando sempre tudo no Limite da inteligência com a sensibilidade, da loucura com a lógica, da poesia com a coisa em si. (idem,pp. 61-62) 
Não deixa de ser curioso, à luz destas observações de Vinicius, lembrar que muito poucos anos antes Jan Mukařovský, no seu ensaio "Em volta da estética do cinema", de 1933, registara:

Devido ao seu carácter significativo, o espaço cinematográfico está muito mais próximo do espaço da poesia que do espaço dramático. Também na poesia o espaço é uma significação: que outra coisa poderia ele ser, se é representado pela palavra? (Mukařovský, 1997, p. 202)

No caso de Mário Peixoto, porém, tal relação de equivalência (cinema puro | poesia pura) ganhara sentido acrescido pelo facto de o realizador ser efectivamente poeta, tendo produzido nesse mesmo ano de 1931 a colectânea Mundéu, não por acaso prefaciada por Mário de Andrade, que não por acaso também caracterizaria a singularidade do livro do realizador no âmbito da poesia da época destacando o "movimento plástico das noções e das imagens":

Os poemas, digamos legítimos, de Mário Peixoto se caracterizam especialmente pela rapidez. Tem-se a impressão de um jato violento, golfadas irreprimíveis. São poemas que nascem feitos, explosões duma unidade às vezes excelente, em que o movimento plástico das noções e das imagens é incomparável dentro da nossa poesia contemporânea. (Andrade, 1997) ${ }^{12}$

Mário de Andrade é o exemplo mais significativo de um pensamento sobre cinema configurado pelo primeiro Modernismo brasileiro ${ }^{13}$-- como notou Flora Süssekind, João do Rio, apesar de sensível ao novo invento, ainda o convocara no volume Cinematographo, de 1909, com sentido muito metafórico; por seu turno, Alcântara Machado, criador do inusitado Pathé Baby, não levaria a cabo qualquer reflexão teórico-crítica sobre a nova manifestação artística (cf. Süssekind, 1987) -, e sem qualquer equivalente no caso português (à excepção eventual de António Ferro), a ponto de:

logo em 1922, ter declarado programaticamente, nas páginas de abertura da primeira Klaxon, "A cinematografia é a criação artística mais representativa da nossa época. É preciso observar-lhe a lição" (Andrade, 1922a $2)^{14}$;

ter constatado com o seu espírito criterioso que "A cinematografia é uma arte que possui muito poucas obras de arte" (Andrade, 1922b, p. 14);

e, nesse mesmo ano, ter proposto a inevitável e muito necessária diferenciação do cinema e do teatro: "O cinema realiza a vida no que esta apresenta de movimento e simultaneidade visual. Diferença-se pois muito do teatro em cuja base está a observação subjetiva e a palavra. O cinema é 
mudo; e quanto mais prescindir da palavra escrita mais se confinará ao seu papel e aos seus meios de construção artística. Segue-se daí que tanto mais cinemática será a obra de arte cinematográfica quanto mais se livrar da palavra que é grafia imóvel. [...] E não se diga que tirar a palavra escrita do cinema seja privá-lo dum meio de expressão. Primeiramente: quanto mais uma arte se conservar dentro dos meios que lhe são próprios, tanto mais se tornará pura" (idem, ibidem).

Todavia, o certo é que o contributo mais importante do Autor de $\mathrm{Ma}$ cunaíma para o campo da reflexão interartística está justamente no facto de Mário ter mesmo observado a lição da nova arte, transpondo-a para a sua própria poética com uma consistência meditativa e reflexiva invulgar, como evidencia o "Prefácio interessantíssimo" a Paulicéia Desvairada (1922), mas, sobretudo, esse texto espantoso que é A escrava que não é Isaura. $\mathrm{O}$ primeiro dá o mote, é certo:

Escrever arte moderna não significa jamais para mim representar a vida atual no que tem de exterior: automóveis, cinema, asfalto. Se estas palavras frequentam-me o livro não é porque pense com elas escrever moderno, mas porque sendo meu livro moderno, elas têm nele sua razão de ser. (Andrade, 1993, p. 74)

Mas é no segundo texto, onde Mário alude explicitamente à "ironia do genial Carlito", referindo-se a Chaplin (1960, p. 213), e se refere também muito expressivamente à "Califórnia de imagens novas, tiradas das coisas modernas ou pelo menos quotidianas" (idem, p. 218), que o escritor desenvolve e aprofunda a sua teoria da imagem poética ("Novas sensações. Novas imagens"; 1960, p. 211) a partir da leitura de teorias de estética cinemática como a de Jean Epstein, ${ }^{15}$ para concluir liminarmente que "na poesia modernista, não se dá, na maioria das vezes, concatenação de ideias mas associação de imagens e principalmente: SUPERPOSIÇÃO DE IDEIAS E IMAGENS" (idem, p. 245), ${ }^{16}$ fazendo assim assentar o seu programa poético nos conceitos de polifonia e simultaneísmo. Procedimento especulativo que, se esteve na base de concepções poetológicas modernistas tão fundamentais como as de Apollinaire ${ }^{17}$ ou Ezra Pound (e a imagista Amy Lowell marca presença digna de nota em A Escrava que não é Isaura, com base numa releitura do seu ensaio Some Musical Analogies in Modern Poetry), não teria qualquer correspondência ensaística digna de nota no Modernismo em Portugal, e ainda menos nos seus primeiros poetas, mas não deixaria de ter expressão 
poemática muito reveladora pela pena do escritor, compositor e fotógrafo Edmundo de Bettencourt, autor do livro O Momento e a Legenda, de 1930, num poema que decerto legitima o juízo radical de Herberto Helder, segundo o qual Bettencourt foi "uma das pouquíssimas vozes modernas entre o milagre do Orpheu e o breve momento surrealista português" (Helder 1963,p. 26):

\section{CINEMA}

No meu olhar, de gosto, ritmo, aroma e seda, com ele, por mágica alameda eu sonho ir ao espaço das visões, que rolam como os mundos, numa sagrada música visível, onde eu me dispersaria...

Ó Cinema, ó maravilha em que eu me possuiria, mas que apenas possuo da sombra, na viva solidão da multidão quieta, entre as carícias do silêncio ao pensamento, sem esforço levado a sofrer, a sentir o que de eterno há num momento!

Em ti, a vida, mais viva porquanto mais alada em fantasia livre, sem noites e sem dias, brutal ou delicada, é síntese movendo-se em transcendência de tristezas e alegrias, numa calma final de nuvens macias como penas, que tempestades não consomem, de encontro ao metálico recorte das projecções estéticas do homem! 
Cinema!

mais que tudo, és

o que lá fora buscam almas inquietas!

Mais que tudo, nos dás

o sonho que das almas sobe

nas imagens dos poetas!

(Bettencourt, 1999, pp. 62-63)

No caso específico do Modernismo brasileiro, talvez não seja erróneo pensar que as maiores concretizações da teoria crítica de Mário de Andrade se tenham verificado mais na prosa do que na poesia, em obras tão decisivas para a hibridização moderna dos géneros literários como Amar, Verbo Intransitivo (1927)do próprio Mário de Andrade, ${ }^{18}$ Serafim Ponte Grande (1933), de Oswald de Andrade, ou Pathé-Baby (1926), Brás, Bexiga e Barra Funda (1927)e Laranja da China (1928), de Alcântara Machado. Em qualquer uma delas, a partir de uma construção estruturalmente assente em processos diversificados de montagem, verifica-se com efeito a consumação daquele simultaneísmo assinalado por Mário de Andrade ("Estou convencido que a simultaneidade será uma das maiores sinão a maior conquista da poesia modernizante", declara ainda em A Escrava que não é Isaura"; p. 273), instaurador de uma muito específica espacialização do tempo que a narrativa pré-cinematográfica ou pré-modernista não tinha podido conhecer. ${ }^{19}$

\section{ABSTRACT}

In this article, a brief reflection is proposed on the relationships between cinema and poetry in the first decades of the $\mathrm{XX}^{\text {th }}$ century in Brazil and Portugal. Special emphasis is given to the modes of reception of the new artistic manifestation by writers of the time as well as to the less predictable authors of themodernist movement.

KEYWORDS:Cinema; poetry; modernism; Limite; Douro, Faina Fluvial; Mário Peixoto; Manoel de Oliveira. 


\section{REFERÊNCIAS}

Agamben, Giorgio, "Difference and repetition: On Guy Debord's films", trad. Brian Holmes, in Tom McDonough (ed.), Guy Debord and the Situationist International, Cambridge Mass., MIT Press, 2002.

Andrade, Mário de, “A escrava que não é Isaura (Discurso sobre algunastendencias da poesía modernista)”, in Obra Imatura, São Paulo, Livraria Martins Editora, 1960. Andrade, Mário de, “A respeito de Mundéu”, in Mário Peixoto, Mundéu, Rio de Janeiro, Sete Letras, 1997.

Andrade, Mário de, "Cinema”, Klaxon, 6, São Paulo, 15 de Outubro, 1922b.

Andrade, Mário de, “Klaxon”, Klaxon, 1, São Paulo, 15 de Maio, 1922a.

Andrade, Mário de, No Cinema, org. Paulo José da Silva Cunha, Rio de Janeiro, Nova Fronteira, 2010.

Andrade, Mário de, Paulicéia Desvairada, in Poesias Completas, ed. crítica de Diléa Zanotto Manfio, Belo Horizonte | Rio de Janeiro, Villa Rica. , 1993

Apollinaire, Guillaume, "L'esprit nouveau et les poètes", Mercure de France(Série Moderne), Paris, Novembro-Dezembro 1918.

Balázs, Béla, Theory of the Film (Character and Growth of a New Art), trad.Edith Bone, Londres, Dennis Dobson, 1952.

Bettencourt, Edmundo de, O Momento e a Legenda, in Poemas de Edmundo de Bettencourt, introd. Herberto Helder, Lisboa, Assírio \& Alvim, 1999.

Bueno, Alexei, "Vinicius de Moraes e o cinema". Texto apresentado ao Colóquio $\mathrm{Meu}$ tempo é quando: Nos 100 Anos de Vinicius de Moraes, Porto, Faculdade de Letras, 18 de Outubro 2013. (no prelo)

Capellaro, Jorge J. V., e Ferreira, Paulo Roberto, Verdades sobre o Início do Cinema no Brasil, Rio de Janeiro, Funarte, 1996.

Cunha, João Manuel dos Santos, A Lição Aproveitada: Modernismo e Cinema em Mário de Andrade, São Paulo, Ateliê Editorial, 2011.

Cunha, Paulo José da Silva, "Mário de Andrade: leitor e crítico de cinema”, Posfácio a Mário de Andrade, No Cinema, Rio de Janeiro, Nova Fronteira, 2010.

Daflon, Claudete, "O percurso escrito da viagem modernista: experimentação em Alcântara Machado e Raul Bopp”, Revista Investigações, vol. 24, 1, Janeiro 2011.

Epstein, Jean, "De quelques conditions de la photogénie", Cinéa-Cine-pour-tous, 19, Paris, 15 de Agosto, 1924.

Epstein, Jean, Bonjour Cinéma!, Paris, Editions La Sirène, 1921. 
Epstein, Jean, La Poésie d'Aujourd'hui: Un Nouvel Etat d'Intelligence, Paris, Editions La Sirène, 1921.

Escorel, Lilian, L'Esprit Nouveau nas Estantes de Mário de Andrade, São Paulo, Humanitas | FAPESP, 2011.

Faria, Octavio de, "Eu creio na imagem...", O Fan, 6, Rio de Janeiro, Setembro 1929.

Faria, Octavio de,Prefácio a Saulo Pereira de Mello, Limite: Filme de Mário Peixoto, Rio de Janeiro, Funarte, 1979.

Fernandes, Filippi, "A ilha e o maçarico: Limite, nos caminhos de um vir a ser", Revista Estudos Hum(e)anos, 6, Janeiro 2013.

Gomes, Paulo Emílio Salles, Cinema: Trajetória no Subdesenvolvimento, São Paulo, Paz e Terra, 1996.

Gonzaga, Adhemar, "História do cinema brasileiro", Cap. 1, Jornal do Cinema, 39, Rio de Janeiro, 1956.

Gonzaga, Adhemar, "História do cinema brasileiro", cap. 2, Jornal do Cinema, 40, Rio de Janeiro, 1958.

Hauser, Arnold, "A era do cinema”, in História Social da Arte e da Literatura, São Paulo, Martins Fontes, 1984.

Helder, Herberto, "Relance sobre a poesia de Edmundo de Bettencourt", introd. a Edmundo de Bettencourt (1999), Poemas de Edmundo de Bettencourt, Lisboa, Assírio \& Alvim. 1963

Hertz, Constança, Mário Peixoto, Cinema e Poesia: Imagens de Permeio com o Mar, Rio de Janeiro, Universidade Federal, 2001.

Klaxon: Mensário de Arte Moderna,São Paulo, 1-9, Maio de 1922-Janeiro de 1923.

Machado, Antônio de Alcântara, Pathé-Baby (1927), ed. fac-similada, São Paulo, Secretaria de Estado da Cultura, 1982.

Mello, Saulo Pereira de,Limite, Rio de Janeiro, Rocco, 1996.

Mello, Saulo Pereira de,Limite: Filme de Mário Peixoto, pref. de Octavio de Faria, Rio de Janeiro, Funarte, 1979.

Moraes, Vinicius de, "Recordando o Chaplin Club", A Manhã, 1 de Agosto 1941.

Moraes, Vinicius de,Cinema, ed. Eucanaã Ferraz, Lisboa, O Independente, 2004.

Moura, Murilo Marcondes de, "A montagem cinematográfica", in Murilo Mendes: A Poesia como Totalidade, São Paulo, Editora da Universidade de São Paulo, 1995.

Mukařovský, Jan, "Em volta da estética do cinema”, in Escritos sobre Estética e Semiótica da Arte, Lisboa, Estampa, 1997. 
O Fan, dir. Almir Castro et alii, 1-6, Rio de Janeiro, 1928-1929.

Oliveira, Valdevino Soares de,Literatura: Esse Cinema com Cheiro, São Paulo, Arte \& Ciência, 1998.

Régio, José, “A Explicação do Homem de Mário Saa”,presença,19, Coimbra, Fevereiro-Março 1929.

Régio, José, “Cinema português”, presença, 33, Coimbra, JulhoOutubro, 1931.

Régio, José, “Cinema português”, presença, 43, Coimbra, Dezembro, 1934.

Ribeiro, António Lopes, "José Régio e o cinema”, in In Memoriamde José Régio, Porto, Brasília Editora, 1970.

Rio, João do, Cinematographo: Cronicas Cariocas, Porto, Livraria Chardron | Lello \& Irmão, 1909.

Süssekind, Flora, Cinematógrafo de Letras: Literatura, Técnica e Modernização no Brasil, São Paulo, Companhia das Letras, 1987.

Viany, Alex, Introdução ao Cinema Brasileiro, Rio de Janeiro, Instituto Nacional do Livro, 1959.

Xavier, Ismail,Sétima Arte: Um Culto Moderno,São Paulo, Ed. Perspectiva, 1978.

\section{NOTAS}

${ }^{1} \mathrm{Na}$ sua tentativa de segmentação das várias fases histórico-estéticas do cinema brasileiro das primeiras décadas, Paulo Emílio Salles Gomes estabeleceu precisamente como primeira faixa temporal o período de 1896 a 1912, belle époque que se encerraria com o colapso generalizado na produção de filmes nacionais (cf. Gomes, 1996,passim).

${ }^{2}$ O Chaplin-Club, fundado a 13 de Junho de 1928, foi o primeiro cineclube latino-americano, tendo sido protagonizado por quatro cariocas: Plínio Süssekind Rocha, Almir Castro, Octavio de Faria e Cláudio Mello. O importantíssimo periódico O Fan (1928-1930)foi o seu veículo de divulgação e de discussão, em cujas páginas - com marcas claras da teoria e prática do cinema impressionista francês - se criticou o “cinema-reprodução» para se valorizar o "cinema-expressão», se menosprezou o "cinema mesquinho» em favor do "cinema universal», e se defendeu a "arte como pura imagem».

${ }^{3}$ Filme sem circulação comercial, Limite foi exibido publicamente em três sessões na Cinelândia do Rio de Janeiro: a 10 de Maio de 1931, no cinema Império; a 17 de 
Maio de 1931, no cinema Capitólio; e a 9 de Janeiro de 1932, no cinema Eldorado. Só voltou a ser exibido para o grande público em Maio de 1978, na Fundação Nacional de Arte (Funarte) (cf. Fernandes, 2013,passim).

${ }^{4}$ N.B. A natureza das relações de Murilo Mendes com o cinema é multímoda e estruturante, como de resto o próprio poeta admitiu muito cedo a Homero Senna, sendo até relativamente simples reconstituir todo um universo de referências e de influências de diversos realizadores e filmes que Murilo foi convocando ao longo da sua obra tendencialmente interartística. Em termos críticos, terá sido provavelmente Murilo Marcondes de Moura o primeiro a dedicar a atenção devida ao assunto, no capítulo "A montagem cinematográfica» do seu estudo consagrado ao Autor, onde o investigador relembra o livro destruído por Murilo, e onde podemos ler: "As idéias de 'supressão das passagens intermediárias' e de 'corte' evocam outro procedimento incorporado pelo poeta de outras artes. Provavelmente nos anos 20, Murilo Mendes escreveu um livro sobre cinema que depois preferiu destruir sem publicação. Anos depois, ele faria uma declaração preciosa a respeito das relações entre a sua poesia e a linguagem cinematográfica: 'Procedi muitas vezes como um cineasta, colocando a 'câmera' ora em primeiro, ora em segundo ou terceiro plano; planos estes representados pelo encontro ou pelo isolamento de palavras, pela sua valorização ou afastamento no espaço do poema'» ("A poesia e o nosso tempo», Jornal do Brasil, Rio de Janeiro, 25 de Julho de 1959; Moura, 1995, p. 31).

${ }^{5}$ Quando Vinicius preparou a exibição de Limite para Orson Welles, em 1942, encontrava-se profundamente envolvido na querela entre o cinema mudo e o cinema sonoro, sobre que se pronunciara nas páginas de $A$ Manhã, defendendo que a verdadeira arte cinematográfica era "arte muda, filha da Imagem, elemento original de poesia e plástica infinitas» e "meio de expressão total em seu poder transmissor e sua capacidade de emoção» (Moraes, 2004, p. 15).

${ }^{6}$ Até então, tinham sido os cómicos mudos a receber a qualificação de "poetas», mas por razões mais vinculadas à actuação do que à composição estética do objecto fílmico.

${ }^{7}$ Saulo Pereira de Mello defende a existência na história do cinema de uma tradição de "filme-poema", com forte presença nos anos 20 do século XX e que não se confundiria com o "cinema de poesia», da qual Limite faria parte. Tal tradição evidenciar-se-ia justamente graças ao abandono da narrativa linear, à procura do rigor formal e da expressão da individualidade do cineasta-poeta compondo versos com imagens (cf. Mello, 1996).

${ }^{8}$ Vinicius comenta ainda: "É preciso dizer mais para acentuar aos grande público a necessidade de se desculpar... publicamente do seu descaso em relação a Limite indo vê-lo como convém na grande exibição que breve vamos promover no Metro Passeio? 
Não creio. Tenho certeza que o público brasileiro pode, se quiser, entender Limite. É uma questão de boa vontade e movimento para a arte. Arte silenciosa, é bom frisar...» (Moraes, 1994, p. 60). N.B. Alexei Bueno: "Limite representou, para os cinéfilos de sua geração [refere-se a Vinicius], especialmente aqueles ligados ao Chaplin Club - já no momento do fim do falado, visto ter sido lançado em 1931 - a realização de um sonho impossível, de uma utopia, o filme - obra sempre caríssima para ser realizada - surgido como um simples desejo de expressão estética, espiritual, o filme sem indústria, sem financiamento, sem estúdio, o filme acima de qualquer narrativa literária ou teatral, conduzindo uma narrativa, sem qualquer dúvida, mas através da imagem, do ritmo, da luz. Limite, de facto, muito pouco conhecido fora do Brasil, é uma das obras-primas do cinema mundial e quase como o canto de cisne do cinema silencioso» ("Vinicius de Moraes e o cinema», ensaio inédito apresentado ao Colóquio Meu Tempo é Quando: Nos 100 Anos de Vinicius de Moraes, realizado na Faculdade de Letras do Porto em Outubro de 2013; no prelo).

${ }^{9}$ Octavio de Faria assinalou justamente que em Limite“aparecem, em primeiro plano, não propriamente as estórias dos personagens, mas - e essa é a principal originalidade cinematográfica - as relações das imagens entre si - dessas imagens que narram o enredo do filme. Não é, positivamente, um filme de estória, de ‘enredo'. É, sim, um filme de ritmo, de imagens que se respondem, uma às outras: um ambiente, uma ou várias 'situações'. Mário Peixoto, ao 'montar' Limite, certamente não deve ter esquecido, nem por um momento, a lição do velho Léon Moussinac: 'Monter um film n'est pas autre chose que rythmer un film'» (Faria, 1979, p. 15). N.B. Giorgio Agambensobre Guy Debord: "The second element, the second transcendental, is stoppage. It is the power to interrupt, the 'revolutionary interruption' of which Benjamin spoke. It is very important in cinema, but once again, not only in cinema. This is where the difference lies between cinema and narrative, the prose narrative with which cinema tends to be compared. On the contrary, stoppage shows us that cinema is closer to poetry than to prose. To bring the word to a stop is to pull it out of the flux of meaning, to exhibit it as such. [...] One could return to Valery's definition of poetry and say that cinema, or at least a certain kind of cinema, is a prolonged hesitation between image and meaning. It is not merely a matter of a chronological pause, but rather a power of stoppage that works on the image itself, that pulls it away from the narrative power to exhibit it as such» (Agamben, 2002, p. 317; sublinhados meus).

${ }^{10}$ Apesar de haver já trabalhos que procuram demonstrar os traços expressionistas de Limite, o certo é que parece ser inegável a marca que o seu opositor, qualificado por Henri Langlois como "impressionismo», deixou no cineasta brasileiro e na concepção da sua obra-prima. O afastamento decisivo do teatro e da literatura, proposto por Louis Delluc e praticado por realizadores como Germaine Dulac, Abel Gance, Jean Epstein ou René Clair, visava fundamentalmente a resistência à proliferação de filmes 
baseados na adaptação de obras literárias, em função de um conceito de argumento elaborado especificamente para o ecrã. Para os artistas do impressionismo francês, como para Peixoto e para a vanguarda dada e surrealista, o essencial do cinema estava na imagem e nas suas potencialidades expressivas, o que os levou a uma aprofundada e inovadora exploração de todas as possibilidades fílmicas oferecidas pelos enquadramentos, pelo ritmo das imagens e pelos jogos de chiaroscuro.

11 "Eu creio na imagem... Na imagem todo-poderosa. Que autentifica o gesto. Que constrói o movimento. Que cria o ritmo. Que revela a alma. Que exprime o pensamento. Que não admite o som e não pode conceber a palavra. Na imagem que é imagem e só pode ser imagem...» (Faria, 1929, p. 4)

${ }^{12}$ Sobre Limite, Mário de Andrade insistira também na questão da "pureza», mencionando-o como "esse filme todo inteiriço um jato de pura arte».

${ }^{13}$ Ismail Xavier defende mesmo que o Modernismo brasileiro não teve grande produção teórico-crítica no campo cinematográfico, enfatizando o facto de "nenhuma publicação dedicada especialmente à crítica e à teoria do cinema ter surgido dos movimentos de renovação artística» (Xavier, 1978, p. 144).

${ }^{14}$ A ênfase dada ao cinema por Mário de Andrade nas páginas da Klaxon é assim, na perspectiva histórica de Ismail Xavier, um exemplo raro de atenção crítica à nova arte por parte dos modernistas nas páginas dos seus periódicos mais importantes (cf. Xavier, 1978, p. 144). Note-se que é o conselho subjacente às palavras inscritas na Klaxon que está na base do título do estudo de João Manuel Santos da Cunha, A Lição Aproveitada: Modernismo e Cinema em Mário de Andrade, que começa justamente por chamar a atenção para o facto de a Klaxon dedicar páginas de todos os seus números (com excepção do n ${ }^{\circ}$ 4) ao cinema (cf. Cunha, 2011, p. 33).

${ }^{15}$ Está já feito o trabalho de reconstituição das fontes francesas do pensamento e da escrita ensaística de Mário de Andrade, muito em particular no que respeita ao seu diálogo activo e assumido com as páginas de L'Esprit Nouveau e com o discurso reflexivo de Jean Epstein, cujo "Le phénomène littéraire» aparece directamente traduzido nas páginas do "Prefácio interessantíssimo" (cf. Escorel, 2011; Figueiredo, 2013).

${ }^{16}$ Como evidenciou o investigador Paulo José da Silva Cunha, a equivalência entre cinema e poesia levada a cabo por Mário de Andrade é de tal forma permanente e determinante nestes anos que, ao relatar a Manuel Bandeira a sua experiência enquanto folião do Carnaval carioca em 1923, o escritor menciona as imagens da memória que lhe teriam surgido graças à "máquina fotográfica, antes cinematográfica» do seu "subconsciente», qualificando essa irrupção lírica como "filme moderníssimo de um poema», desenrolado no "écran das folhas brancas», expressões que, no entender de Cunha, "flagram a sua absorção da linguagem cinematográfica: a página que é tela, e versos que são as imagens ali projetadas, seguindo mecanismos do inconsciente. 
Traduzem recursos, choque de imagens e palavras, simultaneidade, estranhamentos que se manifestam, tanto na poesia, quanto no cinema, por meio da montagem ou da justaposição» (Cunha, 2000).

${ }^{17}$ Não esqueçamos que é justamente Apollinaire, de tanta influência no primeiro momento modernista brasileiro, um dos primeiros pensadores a propor a inevitabilidade do vínculo entre o cinema e a literatura, por via da poesia, logo em 1917, no programático L'Esprit Nouveau et les Poétes, onde constatava com toda a lucidez: "Il eût été étrange qu'à une époque où l'art populaire par excellence, le cinéma, est un livre d'images, les poètes n'eussent pas essayé de composer des images pour les esprits méditatifs et plus raffinés qui ne se contentent point des imaginations grossières des fabricants de films. Ceux-ci se raffineront, et l'on peut prévoir le jour où le phonographe et le cinéma étant devenus les seules formes d'impression en usage, les poètes auront une liberté inconnue jusqu'à présent.[...] Les poètes veulent [...] enfin, un jour, machiner la poésie comme on a machiné le monde. Ils veulent être les premiers à fournir un lyrisme tout neuf à ces nouveaux moyens d'expression qui ajoutent à l'art le mouvement et qui sont le phonographe et le cinema» (Apollinaire, 1918, pp. 385-396).

${ }^{18}$ Que, em carta de 1923 a Sérgio Milliet sobre a génese da obra, chega mesmo a utilizar o adjectivo "cinematográfico», como de resto fará a propósito da obra de Oswald A Estrela de Absinto (cf. Duarte, 1971, p. 273).

${ }^{19}$ Como lembra com toda a pertinência Claudete Daflon no seu ensaio "O percurso escrito da viagem modernista: experimentação em Alcântara Machado e Raul Bopp», este procedimento foi sublinhado por Arnold Hauser na sua leitura das consequências decisivas que o cinema provocou na literatura das primeiras décadas do século XX (cf. Daflon, 2011, p. 31; Hauser, 1984; Süssekind, 1987, p. 48).

Recebido em: 26 de maio de 2015

Aceito em: 15 de agosto de 2015 